\title{
Characteristics of Twitter Use by State Medicaid Programs in the United States: Machine Learning Approach
}

Jane M Zhu ${ }^{1}$, MD, MPP, MSHP; Abeed Sarker ${ }^{2}, \mathrm{PhD}$; Sarah Gollust ${ }^{3}$, PhD; Raina Merchant ${ }^{4}$, MD, MSc; David Grande ${ }^{5}$, MD, MPA

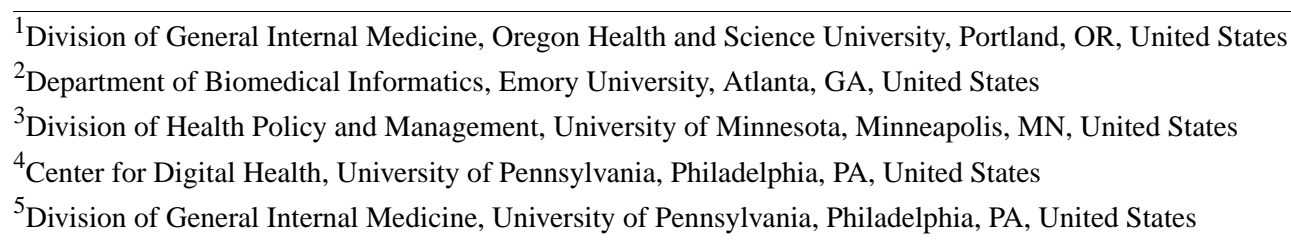

Corresponding Author:

Jane M Zhu, MD, MPP, MSHP

Division of General Internal Medicine

Oregon Health and Science University

3181 SW Sam Jackson Park Road

Portland, OR, 97239

United States

Phone: 15034945040

Email: zhujan@ohsu.edu

\section{Abstract}

Background: Twitter is a potentially valuable tool for public health officials and state Medicaid programs in the United States, which provide public health insurance to 72 million Americans.

Objective: We aim to characterize how Medicaid agencies and managed care organization (MCO) health plans are using Twitter to communicate with the public.

Methods: Using Twitter's public application programming interface, we collected 158,714 public posts ("tweets") from active Twitter profiles of state Medicaid agencies and MCOs, spanning March 2014 through June 2019. Manual content analyses identified 5 broad categories of content, and these coded tweets were used to train supervised machine learning algorithms to classify all collected posts.

Results: We identified 15 state Medicaid agencies and 81 Medicaid MCOs on Twitter. The mean number of followers was 1784 , the mean number of those followed was 542, and the mean number of posts was 2476 . Approximately $39 \%$ of tweets came from just 10 accounts. Of all posts, $39.8 \%(63,168 / 158,714)$ were classified as general public health education and outreach; $23.5 \%(n=37,298)$ were about specific Medicaid policies, programs, services, or events; $18.4 \%$ ( $n=29,203)$ were organizational promotion of staff and activities; and $11.6 \%(n=18,411)$ contained general news and news links. Only 4.5\% ( $\mathrm{n}=7142)$ of posts were responses to specific questions, concerns, or complaints from the public.

Conclusions: Twitter has the potential to enhance community building, beneficiary engagement, and public health outreach, but appears to be underutilized by the Medicaid program.

(J Med Internet Res 2020;22(8):e18401) doi: 10.2196/18401

\section{KEYWORDS}

medicaid; public health; health communication; community engagement; social media

\section{Introduction}

Approximately $20 \%$ of online adults use Twitter [1], a social media platform that allows users to share short messages ("tweets"). With over 500 million tweets per day on topics

including health-related issues, Twitter is a potentially valuable tool for public health officials to engage the public. Prior studies suggest that overall social media use is independent of educational attainment, race/ethnicity, education, income, and health care access [2]. Twitter use is also significantly higher in young adults compared with older age groups, which maps 
well to the Medicaid population, of which $93 \%$ are aged $<65$ years and $80 \%$ are aged $<45$ years [3]. However, evidence suggests that these platforms are currently underutilized. A minority of local public health departments and federal health agencies in the United States use Twitter [4], and these accounts typically have low public engagement [5].

Twitter may be particularly useful for state Medicaid programs, which together constitute the single largest source of public health insurance in the United States, covering 72 million children, older adults, people with disabilities, and low-income populations. Medicaid is currently undergoing a variety of program and policy changes, including eligibility expansion to low-income childless adults; establishment of work requirements for some enrollees; delivery system reforms like accountable care organizations and value-based payment models; and addressing emerging public health priorities like substance use disorder treatment. Given this context, there are significant opportunities for state agencies to better understand, respond to, and engage with the diverse needs of Medicaid-eligible and Medicaid-enrolled populations [6] and to communicate with the general public as a key stakeholder. Despite this potential, to our knowledge no prior study has examined the extent to which Medicaid agencies and health plans are using Twitter to communicate with the public.

\section{Methods}

We identified active Twitter profiles of state Medicaid agencies and Medicaid managed care organizations (MCOs), which are health insurance plans that contract with states to provide Medicaid health benefits and related services. We included the latter group because more than $70 \%$ of Medicaid beneficiaries receive their care through comprehensive managed care plans. To identify Medicaid MCOs, we used the Kaiser Family Foundation's publicly available Medicaid Managed Care Market Tracker [7], which lists all Medicaid MCOs and their parent firms across all 50 states and the District of Columbia. For each state, we searched Twitter, agency websites, and Google to identify and verify relevant Medicaid agency and MCO accounts. Our focus was on state-level Medicaid programs and plans, so we excluded accounts of higher-level governmental agencies (eg, Department of Health and Human Services), parent firms of managed care plans operating across multiple states, and professional accounts of individual Medicaid administrators and leadership.

We used the Twitter public application programming interface [8] to collect a total of 158,714 public posts by the identified accounts, spanning March 2014 through June 2019. To conduct content analysis on these tweets, we manually coded 800 tweets and developed a coding scheme with 5 broad categories of tweet content (Table 1). Three coders independently coded identical samples of tweets, and resolved disagreements and updated the coding guidelines via discussion. Two coders then reviewed a new set of 5338 tweets (excluding retweets), yielding an intercoder agreement of 0.78 using Cohen over 998 overlapping tweets. Tweets that could not be categorized as belonging to one of the 5 categories were labeled "Other" $(n=198)$.
We used the coded tweets to train and evaluate supervised machine learning algorithms, experimenting with four approaches: naive Bayes, support vector machines, random forests, and an ensemble of these three classifiers, which combined the predictions of the independently trained classifiers using predetermined rules [9]. The ensemble classifier obtained the best performance when evaluated using the manually annotated labels, with an accuracy of $74.1 \%$, and therefore we used this classifier to automatically classify all the posts in our data set.

\section{Results}

We identified 96 Twitter accounts, including 15 state Medicaid agencies and 81 Medicaid MCOs (out of 51 total state Medicaid agencies and 323 Medicaid MCOs). Among these accounts, the mean number of followers was 1784 (range 2-38,352, median 1434), the mean number of those followed was 542 , and the mean number of posts was 2476. Twitter accounts had been active for a mean of 79 months, and approximately $39 \%$ of tweets came from just 10 accounts.

The most active accounts in terms of number of tweets were those of health plans, including Fidelis (New York, @FidelisCare, 14,748), HAP Midwest Health Plan Inc (Michigan, @hapmichigan, 12,598), Hawaii Medical Service Association (Hawaii, @ AskHMSA, 12,568), Blue Cross Blue Shield of Texas (Texas, @BCBSTX, 12,157), and UPMC Health Plan (Pennsylvania, @UPMCHealthPlan, 8302). Top accounts in terms of follower count were also health plans, including Fidelis $(38,352)$, UPMCHealthPlan $(14,845)$, Blue Cross Blue Shield of Texas (9355), Seton Health Plan (Texas, @ setonfamily, 8326), and Anthem Blue Cross Partnership Plan (California, @ AnthemBC_News, 7173). In comparison, top Medicaid agencies in terms of follower count included Ohio (@OhioMedicaid, 3165), Massachusetts (@MassHealth, 2223), Washington (@WA_Health_Care, 1858),Colorado (@CHCPF, 1794), and Georgia (@GADCH, 1596).

Of all posts $(\mathrm{N}=158,714), 39.8 \%(\mathrm{n}=63,168)$ were classified as general public health education and outreach; $23.5 \%(n=37,298)$ constituted outreach about specific Medicaid policies, programs, services, or events; $18.4 \% \quad(n=29,203) \quad$ contained relationship-building content including organizational promotion of staff and activities; and 11.6\% ( $\mathrm{n}=18,411)$ contained general news and news links (Table 1$)$. Only $4.5 \%(n=7142)$ of the tweets were customer service responses to specific questions, concerns, or complaints from other users. Additionally, $2.2 \%$ $(n=3492)$ of the tweets did not fit within these categories and were classified as "Other."

The majority of posts received little or no engagement from the public, with only $1 \%$ of tweets having 9 or more likes, or 6 or more retweets. Tweets with more active engagement were more likely to contain words that conveyed actions directed at the public, like "email," "assist," "send," and "contact" (see sample tweets in Table 1). 
Table 1. Frequency and types of posts from Medicaid agencies and managed care organizations on Twitter $(\mathrm{N}=158,714)^{\mathrm{a}}$.

\begin{tabular}{lll}
\hline Category & Definition & Example \\
\hline $\begin{array}{l}\text { Public health educa- } \\
\text { tion }\end{array}$ & $\begin{array}{l}\text { Public health announcements about prevention, disease } \\
\text { conditions, vaccinations, resources, and provision of } \\
\text { general health-related information or health-seeking } \\
\text { behaviors. }\end{array}$ & $\begin{array}{l}\text { Learn the symptoms for each type of gynecologic } \\
\text { cancer. If you have some of the symptoms, talk to } \\
\text { your provider. https://t.co/UPxaBrxY5R }\end{array}$
\end{tabular}

Outreach about spe- Information to raise awareness of specific services, cific Medicaid poli- programs, and events offered by Medicaid, directed cies and programs toward consumers

- All SoonerCare members are required to have $37,298(23.5)$ a valid Oklahoma mailing address on file $\mathbb{E}$ Don't have your Oklahoma address listed on your account? Update your information today at https://t.co/AEkZDU7W4E.

- Unsure if your insurance is still active or if you need to reapply? Call \#HUSKYHealth at 1.800.859.9889 for help.

Relationship building or promotional

Posts directed at a general audience that intends to elicit consumer engagement (responses, replies, likes, feedback), including promotion of agency staff and accomplishments, and greetings.

General news and announcements

Press releases, links to news articles, general announcements

Responses from the plan or agency directed toward a specific question or complaint raised by a consumer and responses to
- What would you want to improve about your Medicaid program?

- Like us on Facebook. Get access to health tips, recipes, and events happening around the state. Visit: https://t.co/0XI6PEfhcq

New post (Three regional agencies team up to support MassHealth consumers with disabilities, complex medical needs) has been published on Advocate News Online - https://t.co/JMfIUOsdhH

@ [redacted] Renewals are done yearly. You will be notified when it's time to renew your coverage.
$29,203(18.4)$

$18,411(11.6)$

$7142(4.5)$ constituents

${ }^{\mathrm{a}}$ Note that $2.2 \%(\mathrm{n}=3492)$ of the tweets did not fit within these categories and were classified as "Other," which is not shown in this table.

\section{Discussion}

\section{Principal Findings}

Social media is one way for Medicaid programs to reach constituents and to launch low-cost health promotion and public engagement campaigns in the face of resource constraints. Our results suggest that despite Twitter's reach among the general public, it is underutilized in the Medicaid program, compared to other public health organizations $[10,11]$.

Twitter has the potential to enhance community building and engagement, which is increasingly a priority for Medicaid programs. Prior work found that two-way communication on Twitter between public health entities and constituents led to an increase in action and awareness that, in turn, resulted in an improvement in community health [12]. However, many public health entities use social media simply to broadcast information without engaging audiences $[4,10]$. While we found that some Medicaid programs are using Twitter, the majority have relatively few followers and overall low engagement with the public. A number of studies point to methods to increase public engagement on Twitter. A study of US children's hospitals using social media found improvements in engagement when posts included pictures and content featuring patient narratives and community partnerships [13]. Other studies in the health care sector have found increased engagement with posts that feature hashtags, URLs, and user mentions [4].
Our study has limitations. Although we used multiple search strategies to verify accounts, we may be missing some active Medicaid accounts. We also excluded a number of umbrella state agencies on Twitter whose activities may include some degree of Medicaid program oversight and outreach, which may lead to underestimation of Medicaid agency presence and activity. Additionally, we used machine learning algorithms to automate content analysis of a large set of tweets, and there may be some misclassification of text across coding categories. Finally, our study focused on Twitter and is not generalizable to other social media platforms that Medicaid agencies and health plans may be using to engage with the public.

\section{Conclusions}

Changes to the Medicaid program have accelerated a number of efforts to increase consumer engagement around disease and care management, cost-sharing, and health care behavior change. As state Medicaid programs confront important public health challenges and expand to serve new populations, social media represents an important and underutilized tool for engaging both Medicaid-eligible individuals and the general public. Future research is needed to understand how social media platforms like Twitter can help these programs improve community engagement around public health programming and interventions. 


\section{Acknowledgments}

The authors would like to thank Alexis Upshur and Vivek Kumar for their assistance with annotating Twitter post content, and Haitao Cai for assistance with data collection. This study was supported by the Robert Wood Johnson Foundation (\#76242). The study sponsor had no role in study design; collection, analysis, and interpretation of data; writing the report; or the decision to submit the report for publication.

\section{Conflicts of Interest}

None declared.

\section{References}

1. Perrin A, Anderson M. Share of US adults using social media, including Facebook, is mostly unchanged since 2018. FactTank.: Pew Research Center; 2019 Apr 10. URL: https://www.pewresearch.org/fact-tank/2019/04/10/ share-of-u-s-adults-using-social-media-including-facebook-is-mostly-unchanged-since-2018/ [accessed 2020-04-22]

2. Chou WS, Hunt YM, Beckjord EB, Moser RP, Hesse BW. Social media use in the United States: implications for health communication. J Med Internet Res 2009 Nov 27;11(4):e48 [FREE Full text] [doi: 10.2196/jmir.1249] [Medline: 19945947]

3. Medicaid and CHIP Beneficiaries at a Glance. Health Care Quality Measures.: Centers for Medicare and Medicaid Services; 2020 Feb. URL: https://www.medicaid.gov/medicaid/quality-of-care/downloads/beneficiary-ataglance.pdf [accessed 2020-03-16]

4. Bhattacharya S, Srinivasan P, Polgreen P. Engagement with health agencies on Twitter. PLoS One 2014 Nov 7;9(11):e112235 [FREE Full text] [doi: 10.1371/journal.pone.0112235] [Medline: 25379727]

5. Neiger BL, Thackeray R, Burton SH, Thackeray CR, Reese JH. Use of Twitter among local health departments: an analysis of information sharing, engagement, and action. J Med Internet Res 2013 Aug 19;15(8):e177 [FREE Full text] [doi: 10.2196/jmir.2775] [Medline: 23958635]

6. Harris JK, Choucair B, Maier RC, Jolani N, Bernhardt JM. Are public health organizations tweeting to the choir? Understanding local health department Twitter followership. J Med Internet Res 2014 Feb 26;16(2):e31 [FREE Full text] [doi: 10.2196/jmir.2972] [Medline: 24571914]

7. Fichtenberg CM, Alley DE, Mistry KB. Improving Social Needs Intervention Research: Key Questions for Advancing the Field. Am J Prev Med 2019 Dec;57(6 Suppl 1):S47-S54 [FREE Full text] [doi: 10.1016/j.amepre.2019.07.018] [Medline: 31753279]

8. Medicaid Managed Care Market Tracker. State Health Facts.: Henry J Kaiser Family Foundation; 2019. URL: https://www. kff.org/data-collection/medicaid-managed-care-market-tracker/ [accessed 2020-02-19]

9. Yoon S, Elhadad N, Bakken S. A practical approach for content mining of Tweets. Am J Prev Med 2013 Jul;45(1):122-129 [FREE Full text] [doi: 10.1016/j.amepre.2013.02.025] [Medline: 23790998]

10. Dietterich T. Ensemble Methods in Machine Learning. In: Multiple Classifier Systems. Berlin, Heidelberg: Springer; 2000:1-15.

11. Thackeray R, Neiger BL, Smith AK, Van Wagenen SB. Adoption and use of social media among public health departments. BMC Public Health 2012 Mar 26;12(1):242 [FREE Full text] [doi: 10.1186/1471-2458-12-242] [Medline: 22449137]

12. Thackeray R, Neiger BL, Burton SH, Thackeray CR. Analysis of the purpose of state health departments' tweets: information sharing, engagement, and action. J Med Internet Res 2013 Nov 11;15(11):e255 [FREE Full text] [doi: 10.2196/jmir.3002] [Medline: 24217361]

13. Wong CA, Ostapovich G, Kramer-Golinkoff E, Griffis H, Asch DA, Merchant RM. How U.S. children's hospitals use social media: A mixed methods study. Healthc (Amst) 2016 Mar;4(1):15-21. [doi: 10.1016/j.hjdsi.2015.12.004] [Medline: 27001094]

\section{Abbreviations}

MCO: managed care organization 
Edited by G Eysenbach; submitted 24.02.20; peer-reviewed by MG Kim, C Mather; comments to author 20.04.20; revised version received 11.05.20; accepted 03.06.20; published 17.08.20

Please cite as:

Zhu JM, Sarker A, Gollust S, Merchant R, Grande D

Characteristics of Twitter Use by State Medicaid Programs in the United States: Machine Learning Approach

J Med Internet Res 2020;22(8):e18401

URL: http://www.jmir.org/2020/8/e18401/

doi: $10.2196 / 18401$

PMID: $\underline{32804085}$

(CJane M Zhu, Abeed Sarker, Sarah Gollust, Raina Merchant, David Grande. Originally published in the Journal of Medical Internet Research (http://www.jmir.org), 17.08.2020. This is an open-access article distributed under the terms of the Creative Commons Attribution License (https://creativecommons.org/licenses/by/4.0/), which permits unrestricted use, distribution, and reproduction in any medium, provided the original work, first published in the Journal of Medical Internet Research, is properly cited. The complete bibliographic information, a link to the original publication on http://www.jmir.org/, as well as this copyright and license information must be included. 